International Journal of Engineering \& Technology, $7(2.13)(2018) 457-459$
International Journal of Engineering \& Technology
SPC
Website: www.sciencepubco.com/index.php/IJET
Research Paper

\title{
Analysis of Leaf Features in Chili Plants Using Automated Color Equalization (ACE)
}

\author{
Basiroh $^{1 *}$, Nuning Kurniasih ${ }^{2}$, Dian Asmara Jati ${ }^{1}$, Nina Zulida Situmorang ${ }^{3}$, Heni Sukrisno ${ }^{4}$, Sujito $^{5}$ \\ ${ }^{1}$ Nahdlatul Ulama Alghazali University Cilacap, Cilacap, Indonesia \\ ${ }^{2}$ Faculty of Communication Sciences, Library \& Information Science Program, Universitas Padjadjaran, Bandung Indonesia \\ ${ }^{3}$ Department of Psychology, Universitas Ahmad Dahlan, Yogyakarta, Indonesia \\ ${ }^{4}$ Department of Education Management, Universitas Wijaya Kusuma Surabaya, Surabaya, Indonesia \\ ${ }^{5}$ Department of English Language Education, IAIN Surakarta, Indonesia \\ *Corresponding author E-mail: basyirohtest@gmail.com
}

\begin{abstract}
Chili is a variety of crop groups that have promising business prospects. To obtain optimal agricultural yield, then the process of plant care and how to planting should be maximal. Constraints often experienced by farmers in the process of planting chili in Magelang regency of Indonesia is a disease of yellow leaves. Some diseases in plants can be identified using precision technology, one of them is by using an image or image-based technology. In previous studies, no one has analyzed using feature extraction using ACE as an analysis to detect plant disease in chili. In this study will extract features using Automated Color Equalization (ACE) which is then classified using SVM (Support Vector Machine) for disease identification based on its leaves. With this method, the accuracy of the extraction results in a combination of $80 \%$ texture features, color feature extraction, and a combination of $80 \%$ color feature texture
\end{abstract}

Keywords: Feature Extraction, Automated Colour Equalization, SVM

\section{Introduction}

Chili is a variety of crop groups (like shrubs) in certain species or species that can be distinguished from other groups based on a particular trait or trait[1]. The location of agriculture in Magelang regency is expanded to 1,723 $\mathrm{Ha}$, with Production Area 2,447 Ha, in 2017 reaching 136,915 quintals of cayenne pepper [1]. The previous year's land area was 1,573 with a production area of 1.594 with production reaching 99,153 rental by 2016[1].

Constraints often experienced by farmers in the process of planting chili in Magelang district is a yellow leaf disease. Some diseases in plants can be identified using technological precision. The method of disease identification can use image-based technology or imagery has been done by some previous researchers. The researcher by [2] the title Fuzzy Inference System Based Unhealthy Region Classification in Plant Leaf Image was examined by K. Muthukannan, P. Latha[3] on the method used image cropping, and the artificial neural network of the researcher still stated the result of the less accurate data. Orchid Disease Detection Using Image Processing and Fuzzy Logic was examined by Muhammad Thaqif bin Mohamad Azmi, and Naimah Mat Isa Selangor[2] researchers used the MoM method, which it said that was not suitable for detecting disease. The three defuzzification methods show that the leaves are least diseased though MoM method May not be suitable because of the result of one pattern. Detection of the unhealthy region of plant leaves using Image Processing and Genetic Algorithm. Vijay Sigh Asst Professor IMS Engg college, Varsha Asst Professor JSSATE Noida, Uttar Pradesh, India and Prof. A K Misra Professor, MNNIT Allahabad, Uttar Pradesh, India [4]. A Predictive Fuzzy Expert System for Diagnosis of Cassava Plant
Diseases is studied by Awoyelu, I. O. \& Adebisi, R. O 2015. Department of Computer Science and Engineering Obafemi Awolowo Unversity, Ile-Ife, Nigeria. In his research using a Fuzzy Expert System method where researchers only specialize in researching the cassava planted to identify or diagnose [5].

The study was investigated by Sanjeev S.Sanaki, R. Arunkumar[6] This study focuses on the existing disease spots on the leaves. Feasbility Study on plant cassava detection using image processing was investigated by Zulkifli ibn Husayn, Aliyeon bin Md Shakaff [7] the researchers only tested the color of the extract alone, so it did not examine further on the accuracy level. Rabia Masood, S.A. Khan, M.N.A. Khan Plants Disease Segmentation using Image Processing I.J. Modern Education and Computer Science [5] researchers only mapped the results of research from other researchers by making literature review of segmentation and algorithm

In previous studies, no one has assessed using feature extraction using ACE as an analysis to detect plant disease in chili. In this study will extract features using automated Color Equalization which is then classified using SVM (Support Vector Machine) for disease identification based on its leaves. This research is raining to know the accuracy of each extract used for disease identification in chili plants. This study uses RGB color space to present the colors.

\section{Methodology}

Data collection was taken from agriculture service and food security, a subsidy of Magelang regency HPT with survey location in Borobudur area, data of chili leaf image good and ill have taken a 
picture using the camera. The result of this step is to get a picture or image of chili leaves.

The image of chili leaves that have been acquired by experts is labeled then the number of labels corresponding to the chili pest disease to be identified. The leaf image is determined according to the data taken from the data collection.

After the acquisition step, the next is the identification of chili disease that has been formed is done by using trial data testing. The test results are how accurate the system used to process plant disease data on chili. The disease identification begins with preprocessing data processing, the purpose of which the data will be tested prepared for the next step is for feature extraction. The result of the feature extraction step is the image area represented in 2 forms, ie, RGB transformation form into grayscale form[7]-[10] and transformation image from RGB shape to ACE shape transformation space. Schaefer combines two popular normalization techniques, namely Grayworld and Max RGB to increase the contrast of color. [11]

The next step process of texture feature extraction by using Automated Color Equalization (ACE) in this step is feature extraction that produces the matrix of each feature. The minimum value of the boundary between colors used to build membership function[11]. The last process of this step is the classification, the classification in this study using SVM (support Vector Machine). This study uses SVM because it is suitable for processing a small amount of data and gives fairly high accuracy.

In general, the description of the research process includes several steps can be seen in the following figure.

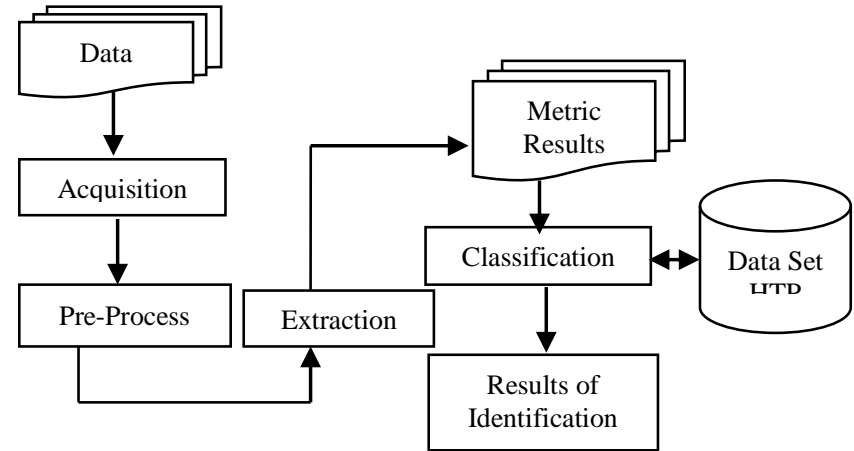

Fig 1:. Research Flow

\section{Results and Discussion}

Here is the process of image segmentation using thresholding. The stages of chili leaf segmentation process begin with the separation of the red channel, green channel and blue channel from RGB channel image.

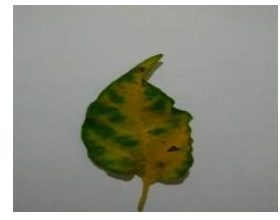

(a) original image
Fig 2:. (a) original image (b) binary image

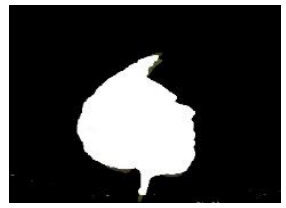

(b) binary image
After the separation of the red channel, green channel and blue channel, RGB channel image is processed by processing using Otsu Thresholding to obtain a binary image.

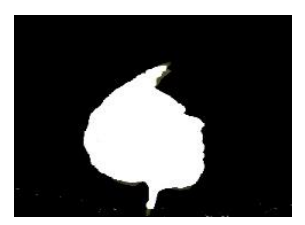

(a) binary image

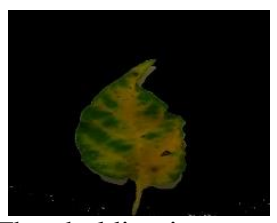

(b) Thresholding image
Fig 3:. (a) binary image (b) Thresholding image results
Image of chili plant leaves that have been cropping and given adjust operation on Matlab, then done the color conversion from RGB color to CIELAB color by using srgb2lab function in Matlab. Results of RGB color conversion to CIELAB color space.

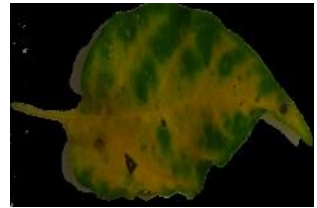

(a) input image

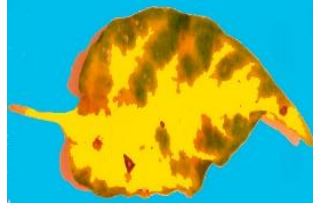

(b) output image
Fig 4:. (a) input image (b) output image

This stage of the ACE algorithm consists of two steps: chromatic/spatial adjustment and dynamic 'tone' alignment. The ACE algorithm stage can be seen in picture 4 which represents the input image, $\mathrm{M}$ is the intermediate image and $\mathrm{O}$ is the Output image whereas the subscript $\mathrm{c}$ shows each RGB channel.

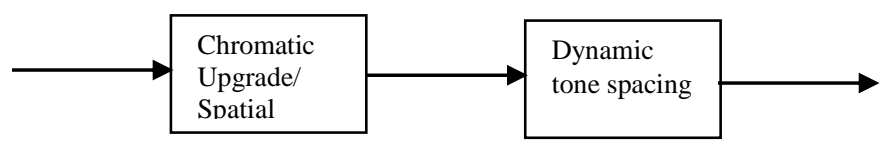

Fig 5:. Steps of ACE Algorithm

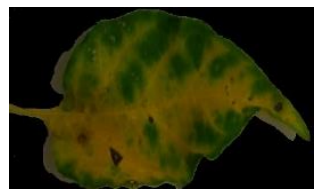

(a) RGB image

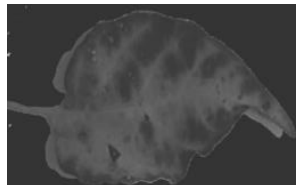

(b) Grayscale image
Fig 6:. Convert (a) RGB Image to (b) Grayscale image

The color feature value between the original image and the preprocess result image is ready to be extracted using the ACE method and used for the next step.

Table 1:. Extraction values of original image and ACE image

\begin{tabular}{|l|c|c|c|}
\hline \multirow{2}{*}{ Image Type } & \multicolumn{3}{c|}{ Value } \\
\cline { 2 - 4 } & Mean & Input & Output \\
\hline Original Image & & & \\
\hline & & & \\
& & & \\
\hline & & & \\
\hline
\end{tabular}

The grayscale image of the staging process has the highest pixel value of 237. The grayscale image pixel value matrix.

Table 2:. Results Matrix of Grayscale Image Pixel Value Picture (b)

\begin{tabular}{|c|c|c|c|c|c|}
\hline 1 & 6 & 2 & 2 & 7 & 3 \\
\hline 4 & 1 & 2 & 1 & 1 & 1 \\
\hline 1 & 3 & 1 & 7 & 1 & 5 \\
\hline 1 & 4 & 1 & 5 & 2 & 3 \\
\hline 3 & 1 & 15 & 2 & 6 & 4 \\
\hline 2 & 1 & 6 & 2 & 4 & 97 \\
\hline
\end{tabular}

The next step is to extract the texture feature using the ACE (Automated Color Equalization) method. The calculated texture feature is a chromatic/spatial increase in Contrast, from 4 directions, ie, $0 \mathrm{o}, 45 \mathrm{o}, 90 \mathrm{o}$, and $135 \mathrm{o}$ simulated as shown in picture 6 .

The value of the Contrast feature of the image is calculated by equation 4 , the correlation feature with equation 5, the energy feature with equation 6 and the homogeneity feature using Eq. 7. The result of texture feature extraction with the ACE method of all directions and average is shown in table 3 below. 
Table 3:. Extraction Image Feature Value With ACE

\begin{tabular}{|l|l|l|l|l|l|}
\hline \multicolumn{1}{|c|}{ Feature } & \multicolumn{1}{c|}{$0^{\circ}$} & \multicolumn{1}{c|}{$45^{\circ}$} & \multicolumn{1}{c|}{$90^{\circ}$} & \multicolumn{1}{c|}{$45^{\circ}$} & \multicolumn{1}{c|}{ Average } \\
\hline Contrast & 0.91852 & 1.912 & 1.255 & 1.394 & 1.3699 \\
\hline Correlation & 0.90217 & 0.78849 & 0.86224 & 0.84593 & 0.84971 \\
\hline Energy & 0.15407 & 0.11829 & 0.12825 & 0.12833 & 0.13223 \\
\hline Homogeneity & 0.84286 & 0.75937 & 0.79517 & 0.78722 & 0.79615 \\
\hline
\end{tabular}

Channel RGB excel 5 methods of measurement in the test scenario with the highest value, after testing as much as ten times testing Grayscale channel has the highest amount of 237. The extrusion of texture features shows that the contrast value of the BD1 image is higher than the other image which means the difference between the higher pixel value of neighbor. The correlation values of all images do not have a high difference. The energy value also in the BD1 image is also the highest showing the similarity of the pixel value to each other BD1 image is highest compared to another image.

Encryption and decryption process with MMBC algorithm is done by using XOR function so it does not require long time for system to process and security improvement can be done better.

\section{Conclusion}

From the results of experiments that have been done in this study it was concluded that identification of chili plant disease type using texture feature with ACE method, color feature using segmentation and classification using SVM method resulted in a combination of results of all features of texture san color features produce a high average value, this is because in this test all the features that exist on the leaves are used entirely as a differentiator between classes of diseases used in this study.

\section{References}

[1] M. F. Handari, "Implementasi Kebijakan Perlindungan Lahan Pertanian Pangan Berkelanjutan di Kabupaten Magelang." Program Magister Ilmu Lingkungan Undip, 2012.

[2] M. T. bin MohamadAzmi and N. M. Isa, "Orchid disease detection using image processing and fuzzy logic," in Electrical, Electronics and System Engineering (ICEESE), 2013 International Conference on, 2013, pp. 37-42.

[3] K. Muthukannan, P. Latha, R. P. Selvi, and P. Nisha "Classification of diseased plant leaves using neural network algorithms," ARPN J. Eng. Appl. Sci., vol. 10, no. 4, pp. 1913-1919, 2015.

[4] I. O. Awoyelu and R. O. Adebisi, "A Predictive Fuzzy Expert System for Diagnosis of Cassava Plant Diseases," 2015.

[5] R. Masood, S. A. Khan, and M. N. A. Khan, "Plants disease segmentation using image processing," Int. J. Mod. Educ. Comput. Sci., vol. 8, no. 1, p. 24, 2016.

[6] S. S. Sannakki, V. S. Rajpurohit, V. B. Nargund, and R. Arunkumar, "Disease identification and grading of pomegranate leaves using image processing and fuzzy logic," Int. J. food Eng., vol. 9, no. 4, pp. 467-479, 2013.

[7] R. R et al., "Visual Cryptography with RSA Algorithm for Color Image," Int. J. Eng. Technol., vol. 7, no. 2.5, pp. 65-68, Mar. 2018.

[8] T. Listyorini, S. Sallu, A. Iskandar, R. T. Manurung, and A. D. Gs, "Holographic Reflection Penglipuran Village Bali," Int. J. Eng. Technol., vol. 7, no. 2.12, pp. 216-219, 2018.

[9] H. Nurdiyanto and R. Rahim, "Enhanced pixel value differencing steganography with government standard algorithm," in 2017 rrd International Conference on Science in Information Technology (ICSITech), 2017, pp. 366-371.

[10] R. Rahim, T. Afriliansyah, H. Winata, D. Nofriansyah, Ratnadewi, and S. Aryza, "Research of Face Recognition with Fisher Linear Discriminant," IOP Conf. Ser. Mater. Sci. Eng., vol. 300, p. 012037, 2018.

[11] Basiroh, Analisis Cita Daun pada tanaman Cabai menggunakan automated colour Equalization. 2018. 